\title{
The Case for Junior Doctor Academic Internships: A Narrative Review of the Published Literature
}

\author{
Yassar Alamri (iD) ${ }^{1,2}$ \\ Xaviour Walker ${ }^{3}$ \\ Tim J Wilkinson (iD) ${ }^{1,2}$ \\ 'Department of Medicine, University of \\ Otago, Christchurch, Canterbury, New \\ Zealand; ${ }^{2}$ Medical Education Unit, \\ University of Otago, Christchurch, \\ Canterbury, New Zealand; ${ }^{3}$ Department \\ of Medicine, University of Otago, \\ Dunedin, Otago, New Zealand
}

Introduction: There is a growing concern with the dwindling academic workforce especially in medicine. Academic internships refer to a hybrid internship during which an intern spends a period of time (typically 3-6 months) in academic/research endeavours. These may serve as initial research experience for junior doctors. However, the merits of this programme have not been assessed to date.

Methods: Studies on integrated academic internships by junior doctors (ie, interns) were included in the present review. The identified articles were grouped into themes. For each article, the methodological approach (and subsequent implemented methods) was noted. The articles were also critically appraised for methodological soundness (both at the study-level, and the outcomelevel).

Results: A total of 1621 publication titles were identified and screened, of which 8 publications were included in the final review. The major themes of the identified publications are: overview of the academic internship programme, evaluation of a programme's experience and outcomes, and other miscellaneous publications.

Discussion: The studies to date have only reported on "soft outcomes", but overall, interns and supervisors alike appear to be satisfied with the programme. Whether the programme increases the likelihood of future academic careers is difficult to establish at this juncture. The academic internship posts appear to be competitive, which reflect their popularity among graduating medical students.

Keywords: medical education \& training, junior doctor, medical student

\section{Introduction}

\section{Background}

Worldwide, there is a growing concern with the dwindling academic workforce (across all disciplines, but particularly in medicine), as the current one continues to age, but without adequate replacement by a new one. ${ }^{1}$ For example, the medical academic workforce in the United Kingdom (UK) witnessed a reduction in the last 10 years, with a subsequent increase in unfilled medical academic vacancies. ${ }^{2}$ In the United States (US), the 'NIH Physician-Scientist Workforce Working Group' recommended an annual intake of approximately 1000 clinician-researchers is required in order to sustain the current academic workforce. ${ }^{3}$

Similar trends have also been observed in Australia. In their report, Hugo and Morriss ${ }^{1}$ demonstrated an academic workforce that has a higher proportion of staff in the older age-groups. This was observed across multiple disciplines, but 
especially evident in nursing and education. Whilst the medical field had also expressed concern vis-à-vis the ageing workforce, the authors did not report any specific data. ${ }^{1}$ Unfortunately, data on the academic workforce in New Zealand are less robust compared with Australia. ${ }^{1}$ However, given the worldwide trends, as well as the similarities between Australia and New Zealand in tertiary education and academic structures, it is very likely that similar trends are present in New Zealand.

\section{Rationale}

Traditionally, medical interns (also known as junior doctors, foundation doctors, house officers, and house surgeons) have rarely been encouraged to partake in research or teaching endeavours-perhaps as a result of their heavy workloads or being perceived as too junior. ${ }^{4}$ However, several previous studies have shown that the more senior a clinician gets, the more patient-care responsibility falls upon them, and therefore, the less time they have for academic endeavours if these have not been previously established. ${ }^{5,6}$ With the recent calls to review and improve the current work practices of interns, ${ }^{7,8}$ it is conceivable that the working week of interns could change -including the introduction of dedicated teaching and research times.

Academic internships refer to a hybrid internship during which an intern spends a period of time (typically 3-6 months) in academic/research endeavours, before or after completing other clinical rotations. The most well-known example of hybrid research-clinical internship model is the UK Academic Foundation Programme (UKAFP) which has been adopted since 2005. ${ }^{9}$ However, other academic internships also exist in various other countries. Therefore, the aim of the present review is to investigate the available literature published on academic internships, and their successes and pitfalls.

\section{Methods}

\section{Eligibility Criteria}

Studies on integrated academic internships by junior doctors (ie, interns) were included in the present review. The exclusion criteria were non-English publications, and studies on research endeavours by non-interns (eg, summer research projects by medical students) or non-medical health professionals (eg, nursing academic internships).

\section{Information Sources}

Three bibliographical databases (MEDLINE ${ }^{\circledR}$, EMBASE $^{\circledR}$ and Google Scholar ${ }^{\mathrm{TM}}$ ) were searched for journal articles. Bibliographies of the included articles were also searched for additional references. The library catalogues of New Zealand's two medical schools (University of Auckland, and University of Otago) were searched for relevant theses.

The next phase of the literature search involved searching for relevant content in medical student journals. These are periodicals in which intern projects and experiences may occasionally be published. However, their content is not reliably indexed in searchable databases. ${ }^{10}$ The websites of most of the existing medical student journals as identified in our previous review; ${ }^{10}$ were searched using the same criteria and strategy used for bibliographical databases.

Finally, official electronic documents were sought from the websites of governmental and non-governmental bodies (namely, the Medical Council of New Zealand, the Medical Board of Australia, UK Foundation Programme, Health Education England, Irish Health Service Executive, and National Institutes of Health). These resources, in particular, were believed to provide valuable information on the programmes' rationale, objectives, and overall structure.

\section{Search and Study Selection}

For each database, a combination of the following keywords was used: "intern", "house officer", 'house surgeon", or "foundation doctor", AND "academic", "research" or "education". The search was conducted in early May 2020. Results of this search that met the inclusion criteria were screened (see Figure 1).

\section{Data Collection and Processing}

The identified articles were grouped into themes. For each article, the methodological approach (and subsequent implemented methods) was noted. The articles were also critically appraised for methodological soundness (both at the study-level, and the outcome-level). Dependent upon the theme of the article, certain aspects of the academic internship programme described in each article were highlighted (eg, programme overview, problems identified, or practical advice). 


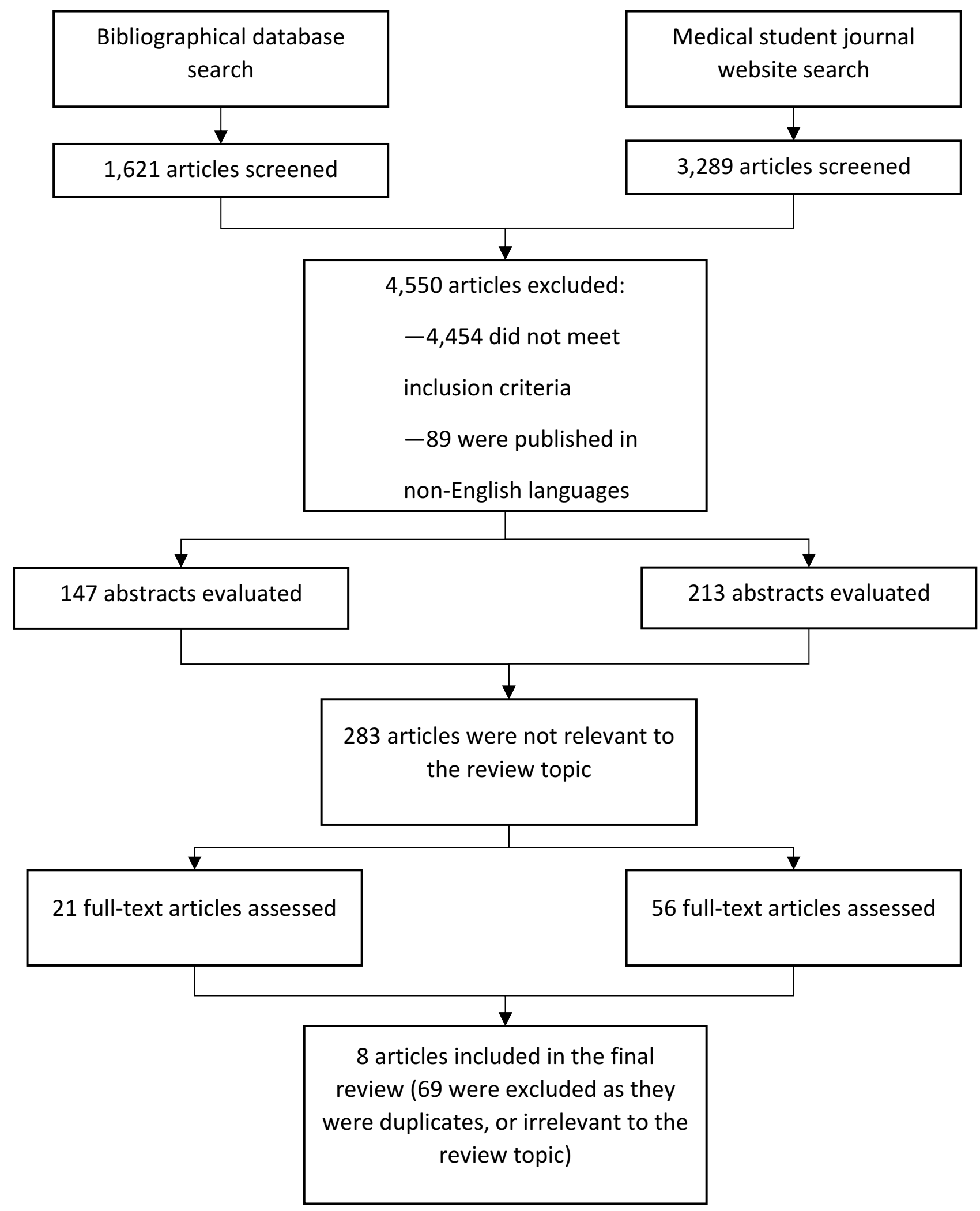

Figure I Process of study selection for the included literature. 


\section{Summary Measures and Biases}

Descriptive statistics were used to describe the quantitative data (eg, the number of interns per academic internship programme). Comparisons of the academic internship were done taking the similarities among the different academic internship programmes at face-value (ie, assuming a similar structure and background). For qualitative data (eg, intern views on the academic internship, summaries of the identified themes were included. Analysis of the combined data sources (ie, a meta-analysis) was not attempted as this is outside the scope of the current project. The literature review is presented in accordance with the PRISMA guidelines. ${ }^{11}$

\section{Results}

\section{Characteristics of Included Studies}

A total of 4910 publication titles were identified and screened, of which 360 were assessed as relevant, and therefore the abstracts was evaluated for eligibility. Of those, 77 publications were read in full-text, which led to the exclusion of 69 . Therefore, the present literature review included 8 publications. The majority of the included literature $(n=7)$ is from UK and Ireland. The major themes of the identified publications are: overview of the academic internship programme, evaluation of a programme's experience and outcomes, and other miscellaneous publications. Table 1 summarises the findings of this review.

\section{Results of Individual Studies}

\section{Overview of the Academic Internship Programme}

The UKAFP was piloted in 2005, with the first cohort of second-year interns beginning academic attachments in 2006, and first-year interns beginning the two-year programme in 2007. ${ }^{9}$ Although the main deficiency that the UKAFP was hoped to rectify was the lack of enthusiasm for academic medicine among senior clinicians, ${ }^{12}$ several upstream barriers were also identified. ${ }^{13}$ These barriers precluded the smooth pursuit of a combined academicclinical career by young clinicians, and included a lack of well-integrated/flexible clinical-academic training routes, as well as a bottleneck of combined clinical-academic posts once training is completed. ${ }^{13}$

The UKAFP is modelled after the traditional "purely clinical" foundation internship programme. This takes place over a period of 2 years, during which the interns undertake activities in research, medical education and/or medical leadership. The delivery of this experience varies by institutions, with some delivering it in the form of weekly day releases (throughout the year), whereas others concentrate it in a 4-month rotation. ${ }^{9}$

Currie et al have recently described the history and details of the Scottish academic foundation programme. ${ }^{14}$ Since the programme's inception in Scotland, the number of academic interns had risen from 54 to 60 (as of 2018). These interns are divided among four deaneries (25 North, 6 East, 18 South East, and 21 West), and make up 7.1\% of all interns working in Scotland in 2018. ${ }^{14}$ Beyond that, the article does not provide any data on the Scottish academic interns.

In Ireland, the academic internship was introduced much more recently. ${ }^{15}$ After its introduction in 2017, Burke and her colleagues assessed the views of senior Irish medical students towards the programme. ${ }^{16}$ Unlike the UKAFP, the Irish academic internship is completed over one year. ${ }^{16}$ As a result, the interns do not have an extended period of time dedicated to research/academia. Rather, they are offered some protected academic time (ie, pre-allocated time for academic activities including teaching and research) on a weekly basis. Each year, the academic interns make up around $3 \%$ of Irish medical interns. $^{16}$

Medical students at Trinity College Dublin were emailed a link to an online survey about the academic internship programme. A total of 50 students $(24.6 \%$ response rate) returned the completed survey. Of those, $21(42 \%)$ were aware of the academic internship programme. The main motives for applying for the academic internship were furthering one's career (more likely to have been the primary motive for female respondents), and the desire to pursue an academic career (more likely to have been the primary motive for male respondents). Students anticipated getting their research published as a result of having protected research time and close mentorship by a supervisor. However, over half of the respondents expressed concerns around the ability to manage clinical duties in addition to research/academic commitments. ${ }^{16}$

The main weakness of the study is its limited scope. Even for a single-institution study, the authors only invited medical students who had a Trinity College email address without explaining their rationale. ${ }^{16}$ It is unclear as to how much time per week is dedicated towards academic work. Additionally, the survey was conducted soon after the 
Table I A Summary of Findings of the Major Studies Included in the Review, and Their Relevance to New Zealand

\begin{tabular}{|c|c|c|c|}
\hline Theme & Author(s) & Methodology & Highlights \\
\hline \multirow[t]{2}{*}{$\begin{array}{l}\text { Overview } \\
\text { articles }\end{array}$} & $\begin{array}{l}\text { Currie } \\
\text { et } \mathrm{al}^{14}\end{array}$ & Essay without collected empirical data & $\begin{array}{l}\text { I. The UKAFP spans over } 2 \text { years-usually with } 4 \text { months } \\
\text { dedicated academic time or weekly academic day releases. } \\
\text { 2. Academic interns make up } \sim 5-7 \% \text { of all interns. }\end{array}$ \\
\hline & $\begin{array}{l}\text { Burke } \\
\text { et } \text { al }^{16}\end{array}$ & $\begin{array}{l}\text { Survey research utilising an online questionnaire } \\
\text { and descriptive statistical analysis }\end{array}$ & $\begin{array}{l}\text { I. The Irish academic internship track has only recently been } \\
\text { introduced. } \\
\text { 2. Academic interns ( } \sim 3 \% \text { of all interns) have dedicated } \\
\text { weekly academic time over a course of one year. }\end{array}$ \\
\hline \multirow[t]{3}{*}{$\begin{array}{l}\text { Experience } \\
\text { and outcomes } \\
\text { studies }\end{array}$} & $\begin{array}{l}\text { Ologunde } \\
\text { et } \text { al }^{17}\end{array}$ & $\begin{array}{l}\text { Survey research utilising an online questionnaire } \\
\text { and descriptive statistical analysis }\end{array}$ & $\begin{array}{l}\text { I. Academic interns rated the programme highly. } \\
\text { 2. Research-oriented projects are more popular than medical } \\
\text { education ones. } \\
\text { 3. Academic interns are eager to formalise their academic } \\
\text { internship into a scholarly degree. } \\
\text { 4. A sizeable proportion of academic interns received no } \\
\text { training in research methodology. }\end{array}$ \\
\hline & $\begin{array}{l}\text { Darbyshire } \\
\text { et al }\end{array}$ & $\begin{array}{l}\text { Convergent mixed-methods research } \\
\text { (questionnaire for interns, and interviews with } \\
\text { thematic analysis for supervisors) }\end{array}$ & $\begin{array}{l}\text { I. Academic interns contributed to significant academic } \\
\text { output. } \\
\text { 2. Academic interns valued their student teaching roles. } \\
\text { 3. Adequate supervision is vital for both interns and } \\
\text { supervisors. } \\
\text { 4. Late contact between intern and supervisor, limited } \\
\text { research time, and inadequate financial compensation are } \\
\text { major barriers. }\end{array}$ \\
\hline & $\begin{array}{l}\text { Berquist } \\
\text { et } \mathrm{al}^{20}\end{array}$ & $\begin{array}{l}\text { Survey research utilising an online questionnaire } \\
\text { and descriptive statistical analysis }\end{array}$ & $\begin{array}{l}\text { A brief introduction to research, with subsequent close } \\
\text { mentorship by established researchers, enables interns to } \\
\text { significantly increase their academic output. }\end{array}$ \\
\hline \multirow[t]{5}{*}{$\begin{array}{l}\text { Miscellaneous } \\
\text { articles }\end{array}$} & $\begin{array}{l}\text { Khajuria } \\
\text { et al. }\end{array}$ & $\begin{array}{l}\text { Survey research utilising an online questionnaire } \\
\text { and descriptive statistical analysis }\end{array}$ & $\begin{array}{l}\text { A live introductory course about the academic internship } \\
\text { aimed at medical students significantly increased their } \\
\text { knowledge about the programme, and confidence in applying. }\end{array}$ \\
\hline & $\begin{array}{l}\text { Nadama } \\
\text { et } \mathrm{al}^{23}\end{array}$ & $\begin{array}{l}\text { Survey research utilising an online questionnaire } \\
\text { and descriptive statistical analysis }\end{array}$ & $\begin{array}{l}\text { An Internet-based seminar about the academic internship } \\
\text { aimed at medical students significantly increased their } \\
\text { knowledge about the programme, and confidence in applying. }\end{array}$ \\
\hline & $\begin{array}{l}\text { Grant } \\
\text { et } \mathrm{al}^{24}\end{array}$ & Essay without collected empirical data & \multirow{2}{*}{$\begin{array}{l}\text { I. Early contact between intern and supervisor is essential. } \\
\text { 2. Academic interns have similar clinical exposure to } \\
\text { traditional interns. }\end{array}$} \\
\hline & $\begin{array}{l}\text { Bodagh } \\
\text { et } \mathrm{al}^{25}\end{array}$ & Essay without collected empirical data & \\
\hline & $\begin{array}{l}\text { Dunne } \\
\text { et } \mathrm{al}^{4}\end{array}$ & $\begin{array}{l}\text { Convergent mixed-methods research } \\
\text { (questionnaire for students, and interviews with } \\
\text { thematic analysis for interns) }\end{array}$ & $\begin{array}{l}\text { I. Medical students rates intern-teachers very highly. } \\
\text { 2. Teaching students enhanced the academic interns' job } \\
\text { satisfaction. }\end{array}$ \\
\hline
\end{tabular}

programme's inception in 2017; therefore, experience with the programme among the authors and students is likely to have been "hypothetical" rather than "applied". This could influence the way in which the questionnaire items were worded by the authors or perceived and answered by the students.

\section{Programme Experiences and Outcomes}

In the first large-scale study of the UKAFP, Ologunde et al surveyed academic interns in the UK. ${ }^{17}$ This cross-sectional study involved an online questionnaire which was sent to all academic interns working in the UK, of whom 56 return the completed questionnaire. The sample was 
almost equally split between males (48\%) and females (52\%); just under two-thirds of the respondents (64\%) were in their second year of the two-year academic internship.

The majority of the respondents rated the quality of the programme, supervision, and career advice received as good or excellent. For the vast majority of the respondents $(82 \%)$ the academic internship was research-based; for the remainder, the academic internship had a medical education or mixed focus. Paradoxically however, $41 \%$ of the academic interns received no training in research methodology and conduct.

Several areas of improvement were voiced by the respondents, chief among which were the desire to be able to complete a post-graduate diploma/certificate based upon the research done during the internship, improved financial assistance, and better academic supervision. Of note, the majority of the respondents $(86 \%)$ denied a measurable reduction in clinical exposure (compared with the traditional internship). Seventy-five percent of the respondents intended to remain in academia, although — for the majority $(63 \%)$ - the academic internship had no influence in that decision.

The main flaw in this study is the very low response rate for which the authors make no attempt to explain. In 2016, a total of 513 academic interns were working in the UK. ${ }^{18}$ Extrapolating from this information, the study by Ologunde and colleagues ${ }^{17}$ had a response rate of $10.9 \%$. Not only does this raise concerns for non-response bias (thus, affecting external validity), but it can also distort the interpretation of some of the reported results. For example, the authors remarked that $63 \%$ of the respondents did not feel that the academic internship influenced their future career intentions; however, one could see why that is when $91 \%$ came to the programme with prior research degrees. It is likely that these individuals had decided on an academic career even before embarking on the academic internship.

Another recent study that evaluated UKAFP is by Darbyshire and colleagues. ${ }^{19}$ These authors conducted a mixed-methods study to evaluate the experiences of interns and their supervisors participating in the academic internships in England. An online survey (which was accessible for 4 weeks in mid-2013 and again in mid2014) was sent to 48 academic interns, of which 34 in total were returned (ie, response rate $44 \%$ in 2013 , and $27 \%$ in 2014). The majority of the respondents (64\%) were satisfied with their academic achievements to date-with sizeable proportions having presented their research findings locally (58.8\%), and nationally/internationally $(52.9 \%)$, and published in peer-reviewed journals (23.5\%). The academic intern responses also identified problems with the programme, including a general lack of a structure to the programme, and the limited protected time for research. About a third (35\%) of the academic interns had teaching responsibilities, and they had perceived this as a highlight.

The authors also interviewed seven supervisors for their insights into the programme. In general, the interviewed supervisors viewed the programme positively. A recurring theme among the interviewees was that unprepared supervisors struggled to deliver their duties; this was particularly the case among supervisors who had only supervised one or two academic interns. They also emphasised several features for the success of an academic internship: enablers, such as early contact between the intern and supervisor, having a worthwhile project, and personal attributes of the intern; and barriers, such as the limited research time, lack of funding, and inadequate statistical support.

This study provides a unique juxtaposition of the interns and supervisors' experience of the UKAFP in North West England. ${ }^{19}$ However, a major weakness of the study is its failure to address the representativeness (or lack thereof) of the intern sample. It is unclear if the authors could distinguish which interns responded to the survey in 2013 versus 2014. One could infer that this was not the case as the authors report two separate response rates, and go on to merge the results. This would potentially mean that some interns responded to the survey twice, whilst others did not respond (twice), thus amplifying the non-response bias. The timing of sending out the intern surveys coincided with the end of the academic year, which may have been appropriate as only would the interns have experienced the programme in its entirety, but this approach does predispose to recall bias. The limited number of supervisor interviews is not out of keeping with qualitative research, and the authors have ensured saturation was achieved in the supervisors' responses; this arm of the study would have benefitted from a comment on the authors' reflexivity.

Thus far, the review has focussed on studies evaluating the UKAFP. However, this report evaluated the outcomes of a 2-hour introductory research workshop that was delivered to interns in a single centre in the US..$^{20}$ Although not a dedicated academic internship per se, this innovative 
intervention was designed to facilitate intern engagement in research early on in their post-graduate career. Modelled after "speed dating", each of the 24 interns met with 13 established researchers individually (6 minutes at-a-time) during which each party talked about their research interests and experiences.

Despite the fact that the majority of the interns (75\%) had prior research experience, only $9 \%$ were involved in a research project pre-intervention. When surveyed 18 months after the intervention, $39 \%$ of the interns commented that the intervention changed their career plans, $48 \%$ had submitted a paper for publication, and $22 \%$ had already published their research. ${ }^{20}$

These results appear highly encouraging, but one ought to keep in mind several major differences to the earlier reports. The concept of "formal mentorship" is much more developed in US post-graduate medical education than it is in the UK, Australia and New Zealand. ${ }^{21}$ The research mentors for this cohort of US interns are likely to have provided significantly more assistance and guidance than talking for 6 minutes to 24 interns. The fact that 39\% of the interns considered changes in career plans imply significantly more engagement with their research mentors than is feasible from a single 2-hour workshop. Finally, longer term data (eg, whether interns actually go on to take academic posts) remain lacking.

\section{Miscellaneous Articles}

Two studies evaluated the effect of providing medical students information about the UKAFP. In the first study, Khajuria and colleagues ${ }^{22}$ organised a national two-day introductory and preparatory course for medical students interested in the UKAFP. This involved a number of lectures, workshops, opportunities to network with current academic interns, as well as conducting mock interviews for students imminently applying to the UKAFP. Compared with pre-course responses, post-course responses indicated improved knowledge and interest in the academic internship, and higher confidence in applying. In 2019 , the same research group ${ }^{23}$ conducted a similar course that was delivered by the Internet (ie, webinar). This, too, showed similar results to the live course. Whilst it is likely the attendees of these courses comprised a higher proportion of students already interested in the UKAFP compared with a truly random group of medical students (ie, selection bias), the studies highlighted some benefit in encouraging and "demystifying" the application process. With the current concerns about large social gathering due to COVID-19, it is perhaps more conceivable that an online course would be more appropriateespecially in areas where the pandemic has not yet been well-controlled.

For prospective applicants, Grant and his colleagues ${ }^{24}$ offer practical advice on the application process given its competitive nature, as well as the highlights and challenges of the academic UKAFP in a letter-to-the-editor. The authors (two of whom were academic interns at the time of publication) implied that the potential for lower levels of clinical exposure (as a result of academic commitments) was offset by the priority afforded to clinical interns in choosing the clinical rotations they desire. ${ }^{24}$ Overall, the authors provided a balanced view of the UKAFP, although it must be noted that they were all affiliated to a single hospital in Northern Ireland.

A similar publication also appears in the literature, ${ }^{25}$ and largely covers the sentiments by Grant et al. ${ }^{24}$ Bodagh and colleagues emphasised the importance of early contact between the prospective academic intern and their supervisor in order to allow for a prompt commencement of their project. Unlike Grant et al, Bodagh and co-authors (two of whom were also academic interns at the time of publication) come from three different institutions, lending more external validity to their piece.

Dunne and colleagues piloted a programme of internled teaching of medical students in a tertiary hospital in Ireland. ${ }^{4}$ Due to the clinical commitments of senior medical staff (who would usually lead the student-teaching sessions), medical students were frequently missing tutorials. As interns are the most junior members of the medical team, they often have the least responsibility in terms of patient-care delivery, and theoretically more team to pursue teaching or research endeavours. ${ }^{6}$

Interns in this study were selected to deliver regular tutorials in Medicine and Surgery to medical students over a two-month period. The investigators then obtained responses from both the intern-tutors (by interviews) as well as medical students (via a questionnaire) about their experience. The intern-tutors valued the experiences as it had improved their own medical and surgical knowledge, as well as enhanced their job satisfaction. The tutorials were well received by the students, the majority $(>75 \%)$ of whom rated several aspects of the tutorials (eg, relevance, detail, teaching style and communication) as "excellent".

These positive findings notwithstanding, the study would appear to have been over-ambitious in its aim to 
evaluate the practicality and efficacy of intern-led teaching due to several major methodological flaws. The study was severely limited in both scope (only 2 intern-tutors) and duration (2 months). The selection of intern-tutors was based upon academic distinction and an interest in teaching, and they were not compensated in any way. Hence, they are likely to represent a select subgroup of driven and intrinsically motivated ie, teaching students because of the activity's inherent enjoyment; ${ }^{26}$ interns, which limits the generalisability of the findings. Furthermore, whilst the authors seem to have utilised a mixed-methods methodology, the reader is given very little information about both the qualitative (ie, intern-tutor interviews) and quantitative (ie, medical student survey questions) arms. Finally, the lack of a "control arm" (ie, a group of medical students taught by senior medical staff) impedes the adequate gauging of the true efficacy of intern-led teaching.

\section{Discussion}

\section{Summary of the Evidence}

Several attempts have been made to boost the interest in academic, teaching and research among medical interns. Although brief initial interventions eg, "speed dating" model employed by, ${ }^{20}$ in conjunction with close mentorship by established clinician-researchers, may kick-start the process, it is likely that more elaborate efforts are needed if sustained results are to be achieved. The prevailing approach to try to achieve this has been the academic internship, which had originated from the UK 15 years ago. $^{9}$

The studies to date have only reported on "soft outcomes" (ie, less tangible or more difficult-to-measure outcomes), but overall, interns and supervisors alike appear to be satisfied with the programme. Whether the programme increases the likelihood of future academic careers is difficult to establish at this juncture. The academic internship posts appear to be competitive, which reflect their popularity among graduating medical students. ${ }^{24}$ Providing interested students with introductory material (via live or online courses) may enhance the prospective applicants' confidence in applying for these competitive positions. ${ }^{22,23}$

Among the highlights of the academic internship to date are the significant research outputs (including conference presentations, and peer-reviewed publications) by the interns, ${ }^{20}$ the valued opportunity to teach medical students, ${ }^{19}$ and the superior performance on clinical (ie, non-academic) rotations compared with traditional interns. ${ }^{17}$ However, several challenges were also identified, including: the lack of funding opportunities, limited protected research time, inadequate introduction to research methodology, and the need for careful balancing of clinical, research and life duties. ${ }^{24,25}$ Educators and government stakeholders ought to implement policies that magnify the benefits of, whilst attempting to reduce the barriers to academic internships - using the UKAFP 15 -year experience as guidance.

\section{Limitations}

Several limitations ought to be acknowledged; these are categorised into three levels: limitations pertaining to the articles comprising this review, limitations related to study outcomes, and overall limitations at the review-level. Each of the articles included in this review was summarised and critiqued (including limitations) in the previous sections. As a whole, the data provided in the included studies come from small samples from the UK. Thus, the generalisability of much published research on this issue is problematic. Furthermore, a few articles contained no empirical data, and were mere iterations of personal opinions and anecdotal experience. Whilst still useful, these accounts are limited by their inherent biases and smaller scopes.

Most of the reported outcomes (eg, opinions and attitudes of academic interns and their supervisors) can be considered "soft outcomes". This is understandable as most academic internship programmes have only existed for less than 10-15 years. This precludes a study of "harder outcomes" such as future career trajectories as it usually takes $8-14$ years after graduation from medical school to fully qualify as a consultant. ${ }^{27}$

The majority of the articles included in this review originated from the British Isles. Whilst one could surmise a potential drawback in this, it is pivotal to remember that the idea of an academic internship was instigated in the UK. Additionally, the identified highlights and problems of the programme are likely applicable to many medical education settings - especially in countries (eg, Australia, New Zealand, Malaysia and Singapore) where the Commonwealth model of post-graduate medical training is implemented. The applicability of these results in other countries (eg, USA) may be limited owing to the differences in training models, and additional location-specific difficulties that make academic pursuits less attractive (eg, student debt load). Therefore, the results and recommendations of this review ought to be contextualised by the reader. 


\section{Data Sharing Statement}

The datasets used and/or analysed during the current study are available from the corresponding author on reasonable request after completion of data publication.

\section{Ethics Approval and Consent to Participate}

Not applicable.

\section{Consent for Publication}

Not applicable.

\section{Author Contributions}

All authors made a significant contribution to the work reported, whether that is in the conception, study design, execution, acquisition of data, analysis and interpretation, or in all these areas; took part in drafting, revising or critically reviewing the article; gave final approval of the version to be published; have agreed on the journal to which the article has been submitted; and agree to be accountable for all aspects of the work.

\section{Funding}

There is no funding to report.

\section{Disclosure}

The authors report no conflicts of interest in this work.

\section{References}

1. Hugo G, Morriss A. Investigating the ageing academic workforce: stocktake; 2010. Available from: http://citeseerx.ist.psu.edu/viewdoc/ download?doi=10.1.1.177.2863\&rep=rep1\&type=pdf. Accessed April 19, 2020.

2. Medical Schools Council. Survey of medical clinical academic staffing levels 2018; 2019. Available from: https://www.medschools.ac.uk/ media/2491/msc-clinical-academic-survey-report-2018.pdf. Accessed July 19, 2021.

3. National Institutes of Health. Report from national institutes of health physician-scientists workforce; 2018. Available from: https://acd.od. nih.gov/documents/reports/PSW_Report_ACD_06042014.pdf. Accessed April 20, 2020.

4. Dunne B, Smyth P, Furlong H, Rakovac-Tisdall A, Murphy D, Sreenan S. Interns as teachers of medical students: a pilot programme. Ir J Med Sci. 2011;180(1):211-214. doi:10.1007/s11845-010-0552-9

5. Alpert JS. Some thoughts on bedside teaching. Am J Med. 2009;122 (3):203-204. doi:10.1016/j.amjmed.2008.10.024

6. Parry J, Mathers J, Thomas H, Lilford R, Stevens A, Spurgeon P. More students, less capacity? An assessment of the competing demands on academic medical staff. Med Edu. 2008;42(12):1155-1165. doi:10.1111/j.1365-2923.2008.03234.x

7. Asch DA, Bilimoria KY, Desai SV. Resident duty hours and medical education policy - raising the evidence bar. $N$ Engl J Med. 2017;376 (18):1704-1706. doi:10.1056/NEJMp1703690
8. Rodriguez-Jareño MC, Demou E, Vargas-Prada S, et al. European working time directive and doctors' health: a systematic review of the available epidemiological evidence. BMJ Open. 2014;4(7):e004916. doi:10.1136/bmjopen-2014-004916

9. UK Foundation Programme Office. Rough guide to the academic foundation programme; 2013. Available from: https://foundationpro gramme.nhs.uk/faqs/2-year-foundation-programme-applications-faq/. Accessed May 06, 2020.

10. Alamri Y. How do medical student journals fare? A global survey of journals run by medical students. Edu Health. 2016;29(2):136-141. doi:10.4103/1357-6283.188756

11. Moher D, Liberati A, Tetzlaff J, Altman DG. Preferred reporting items for systematic reviews and meta-analyses: the PRISMA statement. PLoS Med. 2009;6(7):e1000097. doi:10.1371/journal.pmed.1000097

12. Medical Schools Council. Academic medicine; 2020. Available from: https://www.medschools.ac.uk/studying-medicine/after-medicalschool/academic-medicine. Accessed May 05, 2020.

13. Modernising Medical Careers. Medically- and dentally-qualified academic staff: recommendations for training the researchers and educators of the future; 2005. Available from: http://www.ukcrc.org/wpcontent/uploads/2014/03/Medically_and_Dentally-qualified_ Academic_Staff_Report.pdf. Accessed May 05, 2020.

14. Currie GP, Messeder S, Walker K. The Scottish academic foundation year programme: what, why and how? $J R$ Coll Physicians Edinb. 2018;48(1):50-53. doi:10.4997/JRCPE.2018.113

15. Health Service Executive. Academic intern track; 2018. Available from: https://www.hse.ie/eng/staff/leadership-education-development/met/ medical-intern-unit/academic-intern-track/. Accessed May 10, 2020.

16. Burke E, Teeling M, Hennessy M. Introduction of an academic internship in Ireland: views of undergraduate medical students. $I r$ $J$ Med Sci. 2019;188(3):1025-1032. doi:10.1007/s11845-0181917-8

17. Ologunde R, Sismey G, Kelley T. The UK Academic Foundation Programmes: are the objectives being met? $J R$ Coll Physicians Edinb. 2018;48(1):54-61. doi:10.4997/JRCPE.2018.114

18. UK Foundation Programme Office. Foundation programme 2016 recruitment stats and facts; 2019. Available from: https://healtheduca tionengland.sharepoint.com/sites/UKFPOT/WebDocs/Forms/ AllItems.aspx?id=\%2Fsites\%2FUKFPOT\%2FWebDocs $\% 2 F 6 \% 2 \mathrm{E} \%$ 20Resources\%2FReports $\% 2$ FStats $\% 20$ and $\% 20$ Facts $\% 20 \mathrm{FP} \%$ $202016 \% 2$ Epdf\&parent $=\% 2$ Fsites $\% 2 F U K F P O T \% 2 F W e b D o c s \%$ $2 \mathrm{~F} 6 \% 2 \mathrm{E} \% 20$ Resources $\% 2 \mathrm{FReports} \& \mathrm{p}=$ true \& originalPath= aHR0cHM6Ly9oZWFsdGhlZHVjYXRpb25lbmdsYW5kLnNoYXJlc G9pbnQuY29tLzpiOi9zL1VLRIBPVC9FVUJ1dzYtcGVRQkJzNWx EOWJOcjBjb0JDdDdYQW9CZUNvLTBLMnhlTWVXUW5nP3J0a W11PTZiUXZabUZOMlVn. Accessed April 29, 2020.

19. Darbyshire D, Baker P, Agius S, McAleer S. Trainee and supervisor experience of the academic foundation programme. $J R$ Coll Physicians Edinb. 2019;49(1):43-51. doi:10.4997/JRCPE.2019.111

20. Berquist JB, Carnes M, Roach MA, Vogelman B. 'Speed dating' workshop to pair interns and researchers. Med Edu. 2010;44 (11):1133-1134. doi:10.1111/j.1365-2923.2010.03806.x

21. Bingmer K, Wojnarski CM, Brady JT, Stein SL, Ho VP, Steinhagen E. A model for a formal mentorship program in surgical residency. $J$ Surg Res. 2019;243:64-70. doi:10.1016/j.jss.2019.04.068

22. Khajuria A, Cheng K, Levy J. Effect of a national focused course on academic medicine for UK candidates applying for a clinical academic programme. J R Coll Physicians Edinb. 2017;47(1):65-69. doi:10.4997/JRCPE.2017.115

23. Nadama HH, Tennyson M, Khajuria A. Evaluating the usefulness and utility of a webinar as a platform to educate students on a UK clinical academic programme. J R Coll Physicians Edinb. 2019;49(4):317322. doi:10.4997/JRCPE.2019.415

24. Grant M, Atalla N, Maxwell AP. So you want to be an academic foundation programme doctor? Ulster Med J. 2017;86(3):215-217. 
25. Bodagh N, Meechan C, Woodland P. The academic foundation programme: a new foundation for academic medicine. $\mathrm{Br} J$ Hospital Med. 2017;78(7):C110-C112. doi:10.12968/hmed.2017.78.7.C110

26. Ryan RM, Deci EL. Self-determination theory and the facilitation of intrinsic motivation, social development, and well-being. $\mathrm{Am}$ Psychol. 2000;55:68-78. doi:10.1037/0003-066X.55.1.68
27. Careers New Zealand. Physician; 2020. Available from: https://www. careers.govt.nz/jobs-database/health-and-community/health/physi cian/how-to-enter-the-job. Accessed April 18, 2020.

\section{Publish your work in this journal}

Advances in Medical Education and Practice is an international, peerreviewed, open access journal that aims to present and publish research on Medical Education covering medical, dental, nursing and allied health care professional education. The journal covers undergraduate education, postgraduate training and continuing medical education including emerging trends and innovative models linking education, research, and health care services. The manuscript management system is completely online and includes a very quick and fair peer-review system. Visit http://www.dovepress.com/testimonials.php to read real quotes from published authors. 